\title{
EDITOR'S STATEMENT
}

This issue marks an important milestone in the growth of the ASA Review of Books: the first as a part of the African Studies Review and the last as an annual publication.

Since 1975, and under the careful editorial guidance of Ken Wylie, Allen Howard, and Barbara Lewis, the Review of Books has been the major effort of the African Studies Association to keep its members informed about recently published scholarship concerning the continent. The $R O B$, however, never really found a fixed place in the publishing program of the Association. And with the recent reevaluation of ASA publishing endeavors, it seemed appropriate to reexamine the function and role of the $R O B$.

During 1981 the Association's Board, Publications Committee, and the editors of the ROB and the African Studies Review considered various alternatives. After much thought, and with considerable support from the membership, a decision was made to merge the two journals. Our hope was that we might rejuvinate the African Studies Review as a major voice in Africanist scholarship.

This issue of the $R O B$ was already in preliminary preparation when these discussions began. Therefore, it is presented in its old format: an annual compendium of reviews and review essays. But there are hints of the changes still to come!

Readers will find discussions of popular, as well as scholarly, works concerning Africa. The editors feel this is an important area which members of the Association must regularly address. There are also brief notes of some works, intended more to inform readers of their contents than to evaluate them.

Beginning in 1982, the African Studies Review will carry reviews of recent works in each of its quarterly issues. There will also be special features focusing on subject areas in need of more careful valuation, with frequent attempts to consider the images of Africa portrayed in popular works, teaching materials, as well as in recently published scholarship.

Of course, in making these changes, we are trying to direct our efforts to the membership. Both the editor of the Review and the review editor would welcome comments, criticisms, and suggestions. It is our desire to make the Review precisely that $-\mathrm{a}$ review in the broadest sense of information and scholarship about Africa.

In making this transition, there are numerous people who have provided invaluable help. The members of the $R O B$ editorial board agreed to serve and to assist in this transition not knowing precisely what the outcome would be. Their efforts have been extremely helpful, even though they will have been constituted as a group for so short a time. Likewise, the members of the Association's Publication Committee-and especially its 1981 chairman, Peter Gutkind-have 
offered useful advice and necessary encouragement. And finally, the Department of History at Murray State University has been most generous in its support; on behalf of the Association, we extend them a special thank you. 